\title{
Photostability of nifedipinein monolaurin solid matrix and micellar solution
}

\author{
Mallory Tough, Abebe Mengesha \\ College of Pharmacy and Health Sciences, Drake University, Des Moines, IA.
}

\begin{tabular}{|c|c|}
\hline ARTICLE INFO & ABSTRACT \\
\hline $\begin{array}{l}\text { Article history: } \\
\text { Received on: } 26 / 11 / 2014 \\
\text { Revised on: } 12 / 12 / 2014 \\
\text { Accepted on: } 26 / 01 / 2015 \\
\text { Available online: } 27 / 02 / 2015\end{array}$ & $\begin{array}{l}\text { The purpose of this study is to evaluate the photostability of nifedipine (NIF) in solid monolaurin (ML)-based } \\
\text { matrix and the micellar solutions thereof. NIF loaded-ML matrices at concentrations of } 1: 1,1: 4 \text { and } 1: 9 \mathrm{w} / \mathrm{w} \text { were } \\
\text { prepared using a fusion-high shear homogenization method and characterized using differential scanning } \\
\text { calorimetry (DSC) and scanning electron microscopy (SEM). The absence of an endothermic melting peak at } \\
173^{\circ} \mathrm{C} \text { in the } 1: 4 \text { and } 1: 9 \mathrm{w} / \mathrm{w} \text { NIF-ML matrices indicates that NIF is in an amorphous state. The } 1: 1 \mathrm{w} / \mathrm{w} \text { NIF- }\end{array}$ \\
\hline $\begin{array}{l}\text { Key words: } \\
\text { Photostability, nifedipine, } \\
\text { monoglycerides, monolaurin, } \\
\text { solid-lipid matrix, micellar } \\
\text { solution. }\end{array}$ & $\begin{array}{l}\text { Stability-indicating HPLC method was developed and validated to quantify NIF and its degradation product. } \\
\text { Photoexposed } 1: 1,1: 4 \text { and } 1: 9 \text { w/w NIF-ML matrices exhibited } 2.1,4.6 \text { and } 17 \text { fold slower first-order } \\
\text { degradation rates as compared to the NIF powder. After } 24 \text { days of exposure, the percent drug remaining in the } \\
\text { 1:9 w/w NIF-ML matrix was } 85 \% \text { as compared to only } 5 \% \text { in pure NIF powder. The micellar solutions exhibited } \\
7 \text {-fold slower degradation kinetics than the aqueous solution. The results of this study indicate that the stability of } \\
\text { nifedipine can be improved by formulation into monoglycerides matrix. }\end{array}$ \\
\hline
\end{tabular}

\section{INTRODUCTION}

Nifedipine, 3,5-dimethyl 2,6-dimethyl-4-(2nitrophenyl)-1,4-dihydropyridine-3,5-dicarboxylate (NIF), is a calcium-channel blocker used for the prophylaxis of angina symptoms, and as an antihypertensive agent by acting as an arterial vasodilator(Gerald, 2005). With a feature common to most compounds of the dihydropyridines class, NIF undergoes degradation when exposed to light (Goerner, 2010; Hayase et al., 1995; Marciniec and Rychcik, 1994; Matsuda et al., 1989; Matsuura et al., 1990) generating oxidized nifedipine (Figure 1). The degradation products have been reported to have no pharmacological activity (Grundy et al., 1994b). The photosensitivity and very low water solubility of NIF are challenging properties that need improvement. The purpose of this study is to formulate and characterize NIF-loaded monoglycerides matrix and assess the stability of the drug in the lipid-based formulation. Photostability testing for drug

\footnotetext{
* Corresponding Author

Abebe E Mengesha, College of Pharmacy and Health Sciences, Drake

University, Des Moines, IA. Email: abebe.mengesha@drake.edu
}

substances and drug products is an integral part of stress testing in the ICH Guideline (ICH, 1997) and it is an essential activity of the pharmaceutical industry. The photostability of nifedipine has been studied in solid state (Grooff et al., 2013; Latosińska et al., 2012; Marciniec and Rychcik, 1994; Matsuda et al., 1989; Teraoka et al., 1999a; Teraoka et al., 1999b), in solution (Matsuura et al., 1990)and in various drug delivery systems (Aman and Thoma, 2002; Grundy et al., 1994b; Helin et al., 1998; Kawabe et al., 2008; Maggi et al., 2003; Pawar et al., 2012; Shende and Markandeeywar, 2010). Several attempts have been proposed to improve the photostability of nifedipine, including film coating (Bechard et al., 1992), complexation of the drug with cyclodextrins (Bayomi et al., 2002), surface modification of microcrystals of the drug using titanium dioxide nanoparticles ( $\mathrm{Li}$ et al., 2006), and complexation with weak cationic-exchange resins (Shende and Markandeeywar, 2010). The inclusion of the drugs in novel formulation matrix represents an approach of growing interest to the problem of lightsensitive drugs (Gambhire et al., 2012; Sapino et al., 2013). Previous studies have shown that lipids can be used to form various structures like liposomes, microemulsions, solid-lipid nanoparticles that play a vital role in stabilizing drugs. 
Monoglycerides, such as glyceryl monolaurate (ML), are self-assembling amphiphilic molecules that form a variety of crystalline structures (Sato, 2001)with useful properties of special interest in drug delivery. These lipids can form vesicles around the drug, entrapping the drug in the fatty acid tails thereby shielding the drug from degradation in the aqueous environment(Patel et al., 2011). Many lipids and lipid-based formulations are known to be nontoxic and biocompatible and to enhance the solubility and permeability of many drugs (Gan et al., 2010; Lai et al., 2009).

With the drug molecules suspended instead of dissolved in the aqueous environment, chemical reactions such as hydrolysis, oxidation, or photolysis are slow or prevented.

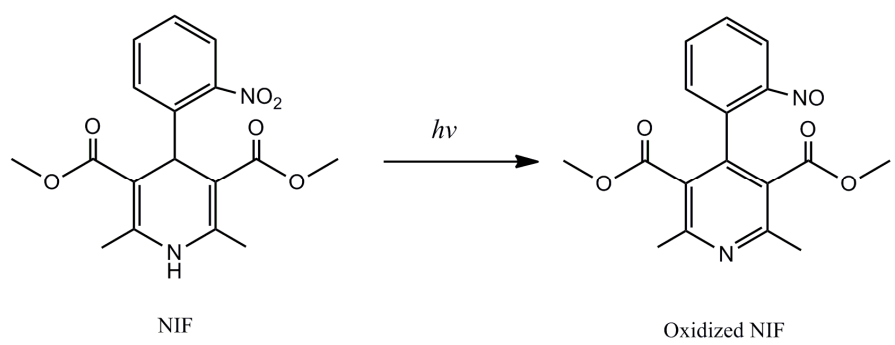

Fig. 1: Nifedipine and its main degradation product.

With the above reasoning, the present study attempt to improve the photostability of nifedipine by loading the drug into glyceryl monolourate matrix to eliminate or reduce the tendency of photo-induced drug degradation.

\section{MATERIALS AND METHODS}

\section{Chemicals}

Nifedipine (NIF) was purchased as the stable polymorph (yellow crystalline powder, melting point $171{ }^{\circ} \mathrm{C}$ ) from Acros Organics. Oxidized nifedipine was purchased from BD Gentest. Monolaurin (ML) was purchased from MP Biomedicals. HPLC grade methanol was purchasedfrom Sigma. Water was obtained through a Barnstead ${ }^{\circledR}$ Water Purification System (Thermo Scientific, Dubuque, IA, USA). All other chemicals used were analytical reagent grade.

\section{Preparation of NIF-ML matrices}

Various compositions of NIF-loaded ML matrices were prepared by a fusion followed by high shear homogenization method. In this, the lipid was melted at $70{ }^{\circ} \mathrm{C}$ and appropriate amount of NIF was dispersed using Ultra Turrax high speed homogenizer to obtain 1:1, 1:4 and 1:9 w/wNIF-ML matrices. The mixtures were then further homogenized by repeating a process of melting in water bath at $70{ }^{\circ} \mathrm{C}$, shaking, followed by chilling in ice-bath $4-5$ times. The NIF-ML matrices were stored at $4{ }^{\circ} \mathrm{C}$ and protected from light.

The samples were characterized using differential scanning calorimetry (DSC) and scanning electron microcopy (SEM). The photostability of NIF in the lipid matrix and the in vitro release were studied using HPLC analytical method.

\section{Characterization of the NIF-MLmatrices}

Differential Scanning Calorimetry (DSC)

The crystallization behavior of NIF in the monolaurin matrices was investigated using a differential scanning calorimetry (DSC1, Mettler Toledo, Columbus, OH). Samples were stored at $4{ }^{\circ} \mathrm{C}$ for at least a week before the DSC study. About $10 \mathrm{mg}$ of sample was weighed into a $40 \mu \mathrm{L}$ aluminum pan and covered with a pierced aluminum lid. Samples were then heated from 25-250 ${ }^{\circ} \mathrm{C}$ at a rate of $10{ }^{\circ} \mathrm{C}$ per min. DSC heating curves of nifedipine, monolaurin and NIF-ML matrices were analyzed. The DSC was calibrated with indium $\left(156.6^{\circ} \mathrm{C}\right)$ and zinc $(419.6$ $\left.{ }^{\circ} \mathrm{C}\right)$.

\section{Scanning Electron Microscopy (SEM)}

The shape and surface structure of the matrices were evaluated by Hitachi S-4800 scanning electron microscope at an accelerating voltage of $3 \mathrm{kV}$ and compared with the SEM of NIF and ML. The samples were sprinkled on an aluminum stub with double-faced adhesive carbon tape and sputter-coated with gold/palladium under an argon atmosphere with high vacuum evaporator. The samples were viewed and analyzed at various magnifications.

\section{Photostability studies}

Irradiation of the NIF-MLmatrices and the micellar solutions thereof were studied using a $70 \mathrm{~W}$, D65 metal halide lamp (Bulbtronics Inc.) according to ICH Q1B, Option 1 guideline. For the solid state stability studies, $10 \mathrm{mg}$ NIF or sufficient amount of NIF-ML matrices containing $10 \mathrm{mg}$ of NIF were placed on glass-watch to form a thin layer of powder film. Samples were then placed at $30 \mathrm{~cm}$ from the lamp. Samples protected from light using amber glass or covered with aluminum foil were used as dark controls. To study the photostability of NIF in micellar solutions, NIF-ML matrices $(1: 1 ; 1: 4$ and $1: 9 \mathrm{w} / \mathrm{w})$ were dispersed in sufficient water and exposed to light. Samples were drawn at certain time interval, filtered and analyzed with the HPLC. Nifedipine dissolved in water was used as a control for the photostability studies in micellar solutions.

\section{High-Performance Liquid Chromatographic analysis of nifedipine}

Assay of nifedipine was determined using high performance liquid chromatography (HPLC) (model LC-10A, Shimadzu equipped with SCL-10A system controller and SPDM20A prominence diode array detector) under the following conditions: C18 reversed-phase column (PhenomenexSynergi, 250 x $4.6 \mathrm{~mm}$, with particle size $4 \mu \mathrm{m}$ and pore size $80 \AA$ ); $236-\mathrm{nm}$ detection wavelength; methanol/water $(70: 30 \mathrm{v} / \mathrm{v})$ mobile phase; $1.0 \mathrm{~mL} / \mathrm{min}$ flow rate. The method was validated in terms of specificity, linearity, LOQ, accuracy and precision.

\section{In vitro release of nifedipine from NIF-ML matrices}

The release studies of nifedipine from the NIF-ML matrices were conducted using cellulose ester dialysis tubing 
(Spectra/Pro® CE Float-A-Lyzer® G2, Spectrum, 1-mL, MWCO 3500-5000 Da, surface area approximately $7.8 \mathrm{~cm}^{2}$ ) at $37{ }^{\circ} \mathrm{C}$. One milliliter of freshly prepared NIF-ML matrix (equivalent to $0.5 \mathrm{mg}$ nifedipine) was placed into a $1 \mathrm{~mL}$ dialysis bag. The dialysis bags were placed in $200 \mathrm{~mL}$ phosphate buffer $(\mathrm{pH}$ 6.8) release medium maintained at $37{ }^{\circ} \mathrm{C}$. Dark condition was maintained throughout the release studies. At selected time intervals, a $1 \mathrm{~mL}$ sample of media was withdrawn and replaced with fresh medium. The nifedipine content was quantified using the developed HPLC method.

\section{RESULTS AND DISCUSSION}

\section{Characterization of the NIF-ML matrices}

Figure 2 shows the DSC thermograms of pure nifedipine, pure monolaurin and NIF-ML matrices (1:1, 1:4 and 1:9 w/w). Thermal analysis showed endothermic peaks at $65.5^{\circ} \mathrm{C}$ and 174.2 ${ }^{\circ} \mathrm{C}$ for pure monolaurin, and nifedipine, respectively. The 1:4 and 1:9 w/w NIF-ML matrices showed a single major melting point at $63.5{ }^{\circ} \mathrm{C}$, whereas the $1: 1 \mathrm{w} / \mathrm{w}$ NIF-ML matrix has two endothermic peaks at 63.6 and $154.3^{\circ} \mathrm{C}$. The disappearance of the NIF endothermic peak in the 1:4 and 1:9 w/w NIF-ML matrices indicate that NIF is found in amorphous state in the lipid matrices. It has been reported that nifedipine has three polymorphic forms: polymorph I ( $\alpha$ or A), melting range: $169-173{ }^{\circ} \mathrm{C}$, polymorph II, melting range: $161-163{ }^{\circ} \mathrm{C}$, and polymorph III, melting point: $150{ }^{\circ} \mathrm{C}(\mathrm{Chan}$ et al., 2004; Gunn et al., 2012; Hirayama et al., 1994). With regards to its melting point, the presently investigated nifedipine standard behaves as polymorph I. The 1:1 w/w NIF-ML matrix showed an endothermic peak at $154^{\circ} \mathrm{C}$ indicating the transformation of NIF into polymorph III.

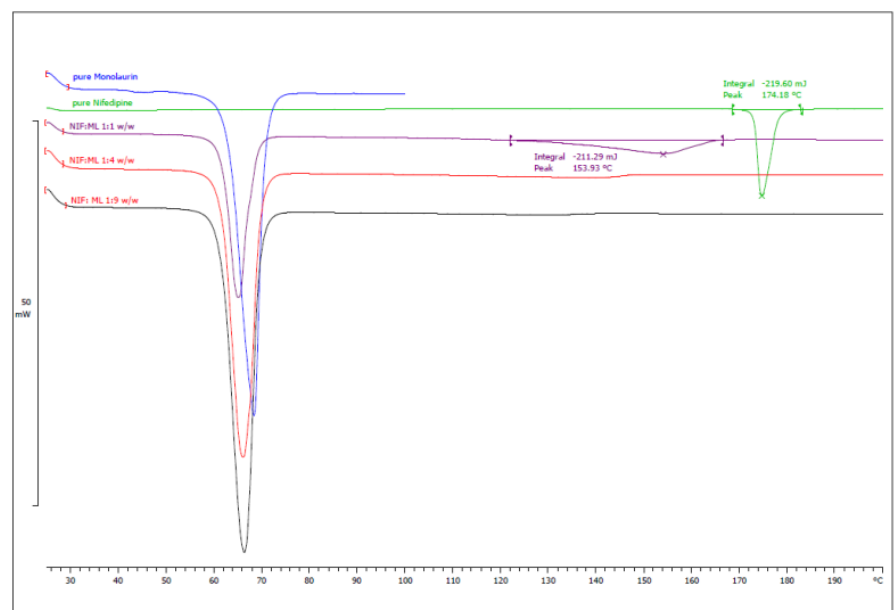

Fig. 2: DSC thermograms of nifedipine crystalline powder (NIF), pure monolaurin (ML), and 1:1; 1:4 and 1:9 w/w NIF-ML matrices.

The occurrence of polymorphism is an important phenomenon since it affects the physicochemical properties such as solubility, bioavailability, and reactivity of the active ingredient. DSC provides important data on the evaluation of stability and compatibility of excipients of a pharmaceutical formulation (Kiss et al., 2006). Interactions between pharmaceutical drugs and excipients may generate several compatibility problems which affect the stability of the formulation. In this study, the absence of new peak on the DSC of NIF-ML matrices confirmed the compatibility of nifedipine and monolaurin. This was further confirmed with the HPLC assay. The 1:4 and 1:9 w/w NIF-ML matrices contain sufficient quantity of lipids to prevent the formation of crystalline form of NIF. The amorphous state has long been recognized as a way to increase the free energy and the apparent aqueous solubility of poorly soluble drugs. The efficiency of different nifedipine amorphous solid dispersions to increase the apparent solubility and drug flux through the intestinal membrane have been reported (Dahan et al., 2013). However, the amorphous phase exhibited a greater rate and extent of photodegradation relative to the corresponding crystalline phase (Grooff et al., 2013). These two competitive objectives need optimization in lipid-based formulation in order to improve solubility and permeability while still maintaining stability. Figure 3 shows the scanning electron microscopy (SEM) of NIF, ML and 1:1; 1:4 and 1:9 w/w NIF-ML matrices. SEM has been commonly used to characterize the surface structure of matrices as well as to visualize the morphological changes during manufacturing process and drug release (Dang et al., 1996). After the preparation of NIFML matrices, the SEM evaluation clearly showed differences in the morphology of the matrices as compare to the NIF and ML standards. The SEM of NIF (Figure 3a) showed a rigid and compact mass.

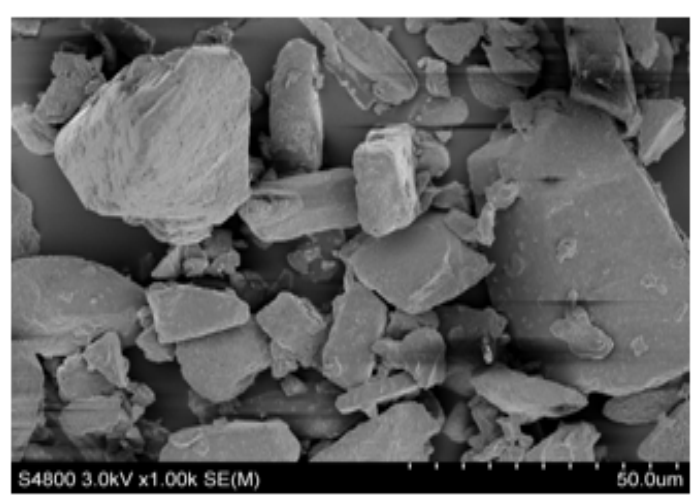

Fig. 3a: SEM of NIF crystals.

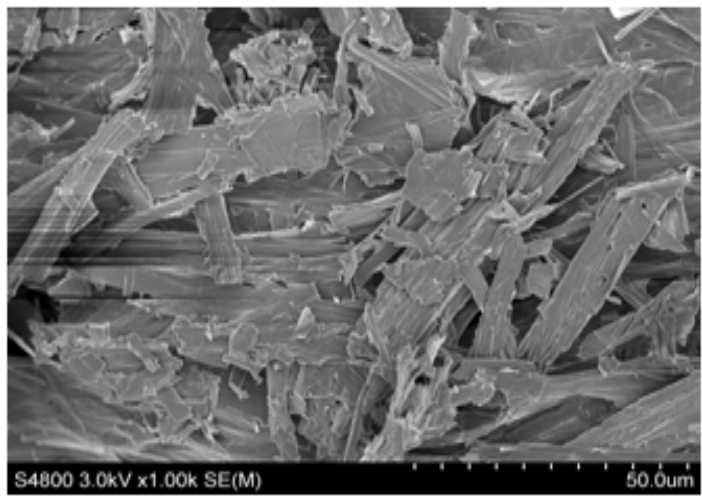

Fig. 3b: SEM of pure ML. 


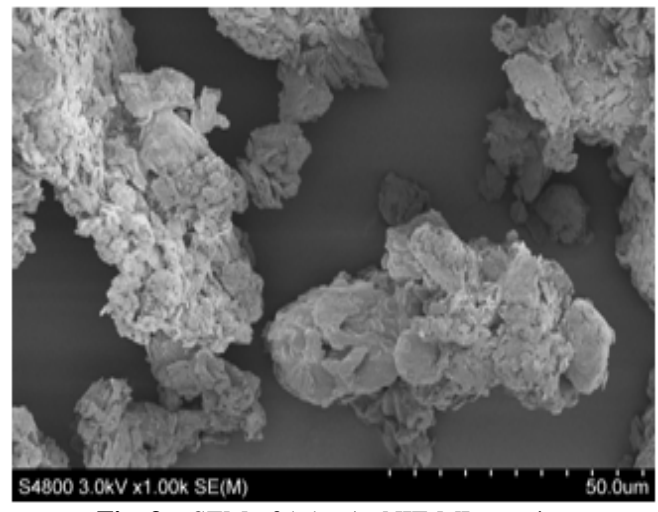

Fig. 3c: SEM of 1:1 w/w NIF-ML matrix.

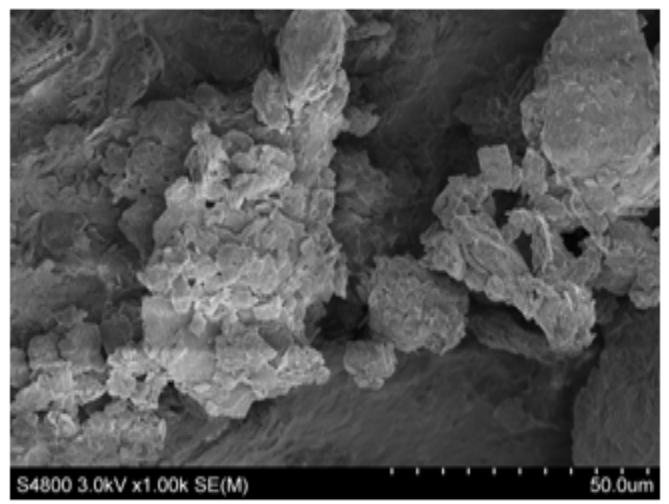

Fig3d: SEM of 1:4 w/w NIF-ML matrix.

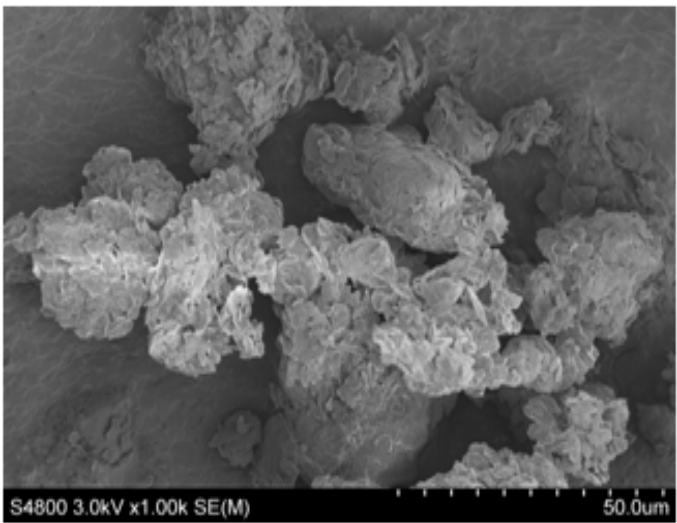

Fig. 3e: SEM of 1:9 w/w NIF-ML matrix.

The NIF sample consisted of large particles with small particles in between and usually flat-surfaced crystals with welldefined and sharp edges. The SEM of the NIF-ML matrices showed that NIF is uniformly dispersed when loaded into the monolaurin matrix (Figure 3c, 3d and 3e).

\section{HPLC analytical method validation}

HPLC analytical method is commonly used to analyze nifedipine and its degradation products in pharmaceutical formulations (Grundy et al., 1994a; Ohkubo et al., 1992; Wu et al., 1993). A stability indicating high-performance liquid chromatography (RP-HPLC) method was developed and used to measure NIF as well as the degradation product.
The RP-HPLC method was linear in the concentration range of $0.1-10 \mu \mathrm{g} / \mathrm{mL}\left(\mathrm{r}^{2}=0.9996, \mathrm{Y}=36263 \mathrm{x}-479.94\right)$. The LOD and LOQ were found to be 0.02 and $0.075 \mu \mathrm{g} / \mathrm{mL}$, respectively. Figure 4 depicts typical HPLC chromatogram of NIF standard, oxidized NIF, as well as NIF-ML matrices after irradiation using $70 \mathrm{~W}$, D65 metal halide lamp (Bulbtronics Inc.) according to ICH Q1B, Option 1 guideline. The major degradation peak was observed at relative retention time of 0.79 relative to nifedipine peak. Comparison between the chromatograms of NIF and the degradation product showed that the HPLC method was specific for NIF (purity > 0.999) and indicated its suitability for use as a stability-indicating method. As shown in Figure 4c, the chromatogram of light exposed samples shows a degradation peak at a relative retention time of 0.79 to nifedipine. The retention time of the degradation product agreed exactly with oxidized nifedipine, the authentic degradation reference (Figure 4b).
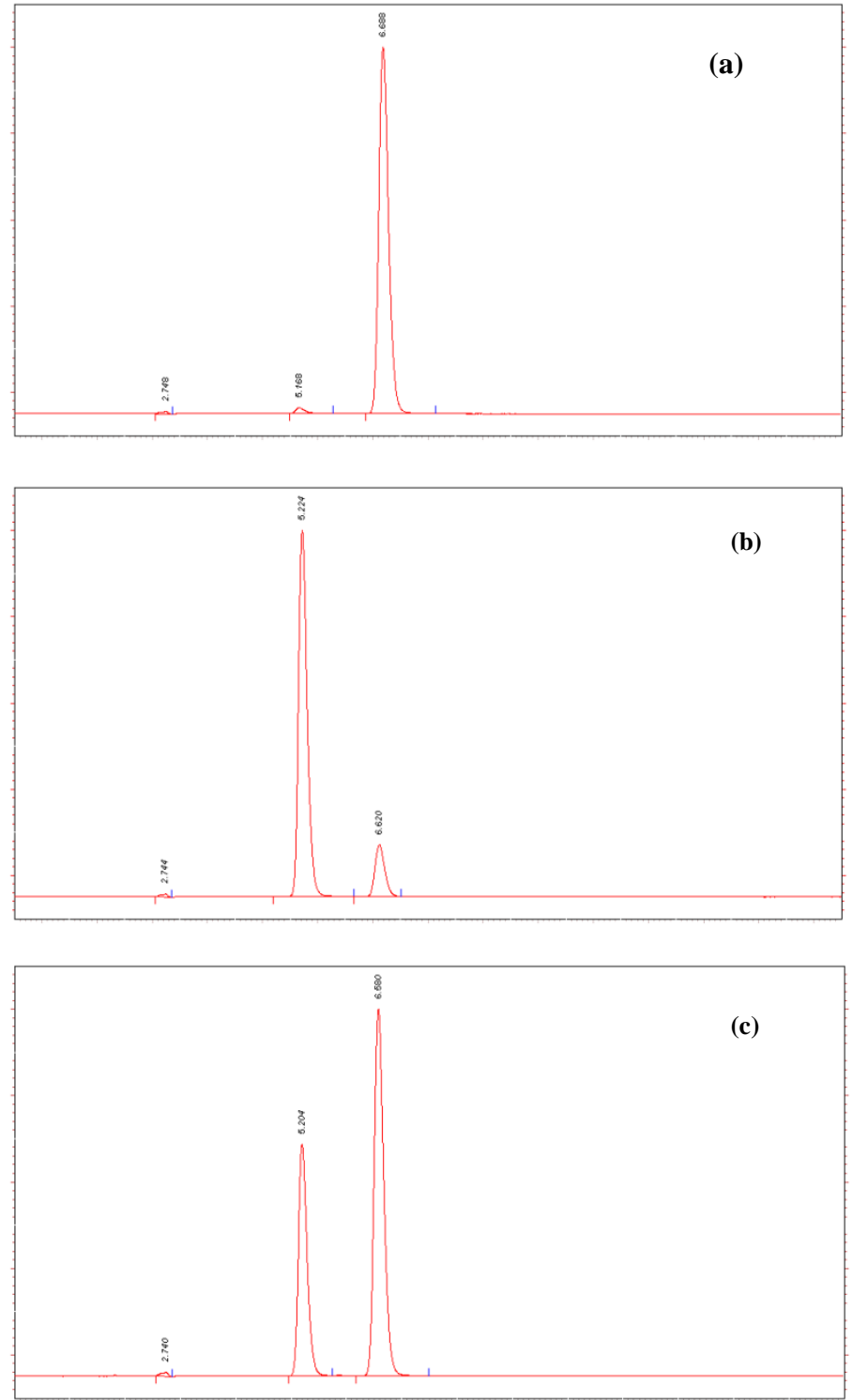

Fig. 4 (a) HPLC chromatogram of NIF standard. (b) HPLC chromatogram of oxidized NIF standard. (c) HPLC chromatogram of NIF-ML matrix exposed to light. 


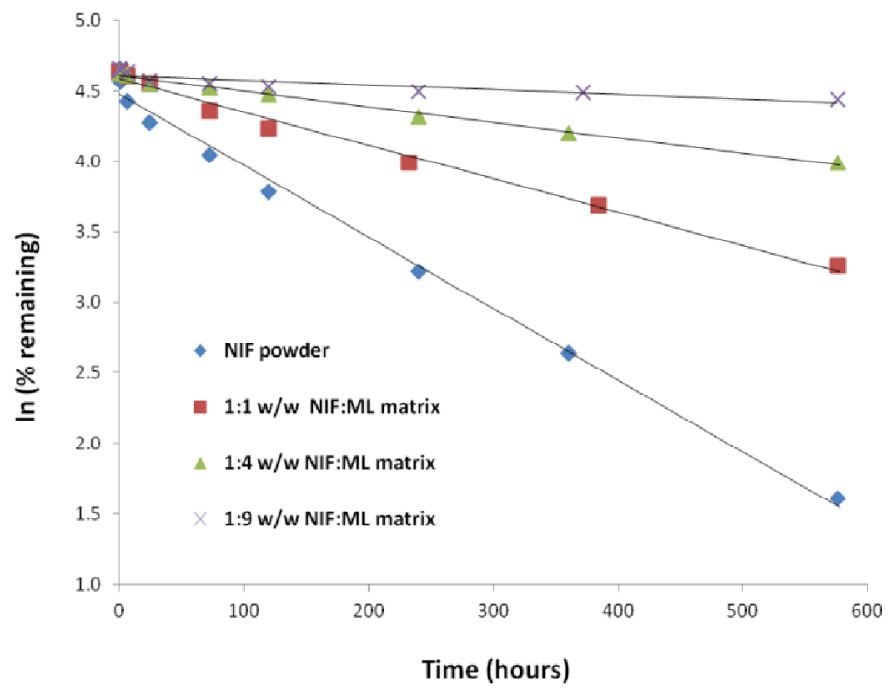

Fig. 5a: First-order plots for the photodegradation of nifedipine in NIF-ML matrices.

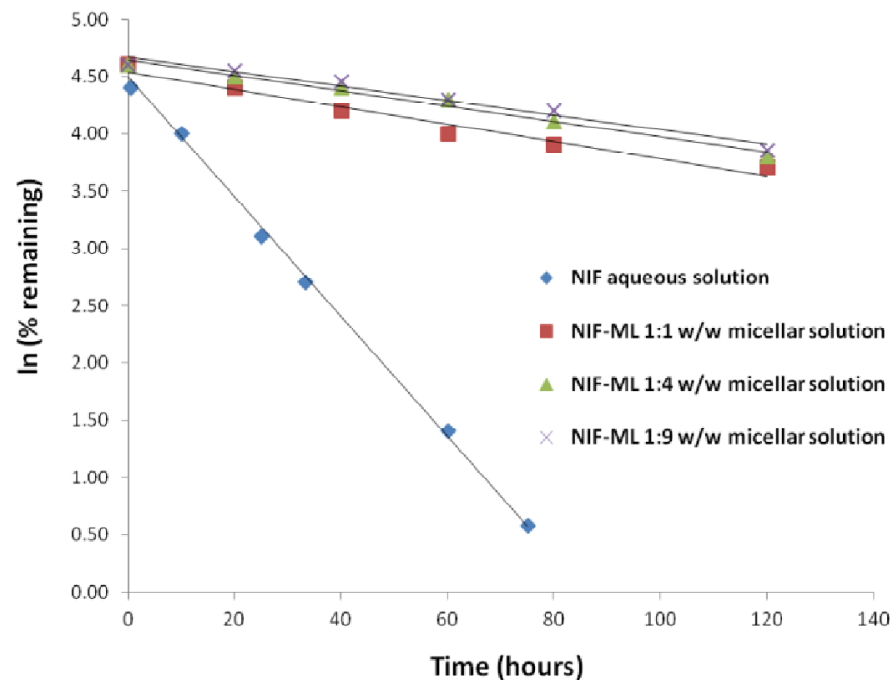

Fig. 5b: First-order plots for the photodegradation of nifedipine in micellar solutions of the NIF-ML systems.

\section{Photostability of nifedipine in NIF-MLmatrices and micellar solutions}

Photodegradation results are shown in Figure 5, in which the logarithms of the percent drug remaining with time have been plotted for the 1:1; 1:4 and 1:9 w/w NIF-ML matrices (Figure 5a) and their corresponding micellar solutions (Figure 5b). Nifedipine is a highly photosensitive drug in solid state as well as in solution that requires protection from light during manufacturing, storage and handling of its dosage forms. Rapid degradation was observed for the unprotected nifedipine as compare to NIF-ML matrices. Photoexposed 1:1, 1:4 and 1:9 w/w NIF-ML matrices exhibited 2.1, 4.6 and 17 fold slower first order degradation rates as compared to the NIF powder, respectively. After 24 days of exposure, the percent drug remaining in the $1: 9 \mathrm{w} / \mathrm{w}$ NIF-ML matrix was $85 \%$ as compare to $54 \%$ in the $1: 4 \mathrm{w} / \mathrm{w}$ and $26 \%$ in the $1: 1 \mathrm{w} / \mathrm{w}$ matrices and only $5 \%$ in NIF powder. One of the challenges in determining photostability of solid drug products is that the light penetration depth is often limited by the absorption of the drug and excipients. The result is that there can be high exposure on the surface of a dosage form, with little exposure at the center. If the light bleaches the drug as it degrades, greater penetration can continue as the reaction proceeds. In contrast, if the drug degradant absorbs strongly, it can limit the penetration depth for photoreaction (Aman and Thoma, 2003). It has been reported that increasing the concentration of NIF or excipients improves NIF photostability (Maafi and Maafi, 2013; Thoma and Kubler, 1997). In order to minimize this variation, the sample size and the thickness of the powder-bed were controlled. The powders were carefully spread to give a layer as homogenous as possible with a thickness below $3 \mathrm{~mm}$. The micellar solutions of NIF-ML mixtures exhibited 7-fold slower degradation kinetics as compared to the aqueous solution of the drug. After irradiation, aqueous solution of NIF decomposed by 50\% in 10 hours and less than $2 \%$ remained after 3 days (Figure $5 b$ ). On the other hand, when NIF is incorporated in the monoglycerides matrix, the degradation rate was slowed. After 3 days of exposure, the percent of drug remaining in the $1: 1 \mathrm{w} / \mathrm{w}$ NIF-ML micellar solution was $49.6 \%$, whereas the percent of drug remaining in the 1:4 and 1:9 w/w NIFML micellar solutions were $60.6 \%$ and $67.0 \%$, respectively during the same period of time. NIF is a hydrophobic drug with an aqueous solubility of about $6 \mu \mathrm{g} / \mathrm{mL}$ at $\mathrm{pH} 7.0$ and anoctanol-water partition coefficient of 3.3 (Squillante et al., 1997). When mixed with monoglycerides, NIF is expected to localize in the long chain hydrophobic moiety of the monolaurin. The hypothesis of this work is that monolaurin in the NIF-ML mixture forms a protective coat around NIF, shielding and thereby reducing the photosensitivity of the drug. Stabilization of NIF in biological samples using sodium dodecyl sulfate micellar solution has been reported (Gil-Agusti et al., 2006).

Photochemical reaction is a complex process, which usually occurs in two stages. The primary reaction which is directly due to the absorption of a photon involves the excited state of the molecule, and followed by the secondary reaction occurring from the intermediates produced by the primary reaction. The secondary reaction could proceed even in the dark (Tønnesen, 2001). Monolaurin may create a protective coat around the NIF reducing the exposure to light and thereby minimizing or preventing the primary reaction. The secondary photochemical reaction proceeds rapidly in solution as compare to solids.

\section{Kinetic interpretations of photostability results}

Photochemical stability of a drug compound in a formulation cannot be predicted simply from the absorption spectrum or stability studies of the drug in a pure solvent. Data must also be obtained for the drug in the final preparation (Tønnesen, 2001). Photodegradation results after the irradiation of NIF-ML matrices and their corresponding micellar solutions are shown in Figure 5, in which the rate of degradations were analyzed according to first-order kinetics using log percentage of NIF remaining versus time (eq. 1).

$$
\ln \left(C_{t}\right)=\ln \left(C_{0}\right)-k t \quad \text { eq. } 1
$$


where, $\mathrm{C}_{\mathrm{t}}$ is the concentration of NIF at time " $\mathrm{t}$ ", $\mathrm{C}_{0}$ is the concentration at time zero and ' $k$ ' is the apparent first-order constant. The curves for NIF photodegradation were found to follow first-order kinetics (Table 2).Previous studies have indicated the apparent first-order photodegradation kinetics of nifedipine at various states (Grooff et al., 2013; Marciniec and Rychcik, 1994; Shamsipur et al., 2003).

Table 1: Differential Scanning Calorimetry Values for ML and the various NIF-ML Formulations

\begin{tabular}{lcccc}
\hline \multirow{2}{*}{ Samples } & \multicolumn{2}{c}{$\begin{array}{c}\text { Melting Endotherm of } \\
\text { ML or NIF-ML }\end{array}$} & \multicolumn{2}{c}{$\begin{array}{c}\text { Melting Endotherm of } \\
\text { NIF }\end{array}$} \\
\cline { 2 - 5 } & $\begin{array}{c}\text { Enthalpy } \\
\mathbf{J g}^{-\mathbf{1}}\end{array}$ & $\begin{array}{c}\text { mp } \\
\left.\text { (peak, }{ }^{\circ} \mathbf{C}\right)\end{array}$ & $\begin{array}{c}\text { Enthalpy } \\
\mathbf{J g}^{-\mathbf{1}}\end{array}$ & $\begin{array}{c}\text { mp, } \\
\left.\text { (peak, }{ }^{\circ} \mathbf{C}\right)\end{array}$ \\
\hline ML-pure & -189.45 & 65.54 & - & - \\
NIF-pure & - & - & -114.89 & 174.18 \\
NIF:ML (1:1) & -98.64 & 63.57 & -23.0 & 154.27 \\
NIF:ML (1:4) & -161.92 & 63.50 & - & - \\
NIF:ML (1:9) & -172.48 & 63.36 & - & - \\
\hline
\end{tabular}

Table 2: Rate constants of photodegradation for NIF in solid form, NIF-ML matrices, micellar and aqueous solutions.

\begin{tabular}{lllll}
\multicolumn{1}{c}{ Solid samples } & $\begin{array}{c}\boldsymbol{K} \\
\left(\boldsymbol{h r s}^{-1}\right)\end{array}$ & $\begin{array}{c}\boldsymbol{t}_{\mathbf{0 . 5}} \\
(\mathbf{h r s})\end{array}$ & $\begin{array}{c}\boldsymbol{t}_{\mathbf{0 . 1}} \\
(\mathbf{h r s})\end{array}$ & $\boldsymbol{r}^{\mathbf{2}}$ \\
\hline NIF powder & 0.0051 & 136 & 20 & 0.9925 \\
1:1 w/w NIF-ML matrix & 0.0024 & 289 & 43 & 0.9903 \\
1:4 w/w NIF-ML matrix & 0.0011 & 630 & 95 & 0.9934 \\
1:9 w/w NIF-ML matrix & 0.0003 & 2310 & 347 & 0.8100 \\
\hline Solutions & & & & \\
\hline NIF aqueous solution & 0.0523 & 13 & 2 & 0.9980 \\
1:1 w/w NIF-ML micellar solution & 0.0076 & 91 & 14 & 0.9670 \\
1:4 w/w NIF-ML micellar solution & 0.0067 & 103 & 16 & 0.9823 \\
1:9 w/w NIF-ML micellar solution & 0.0063 & 110 & 17 & 0.9719 \\
\hline$t$ is expressed in hours & & & &
\end{tabular}

The degradation of NIF was evaluated on the basis of kinetic photodegradation constant $(k)$, half-life time $\left(t_{0.5}\right)$ and time for $10 \%$ degradation $\left(t_{0.1}\right)$ with respect to the initial concentration of NIF. Kinetic analysis (Table 2) of the experimental data showed first-order degradation kinetics in the solid monoglycerides matrix as well as the corresponding micellar solutions. The half-life of NIF powder was 5.7 days and it increased to 12 days for $1: 1 \mathrm{w} / \mathrm{w}$ NIF-ML matrix, and 26.3 and 96.3 days for 1:4 and 1:9 w/w NIF-ML matrices, respectively.

\section{In vitrorelease of nifedipine from NIF-ML matrices}

The mechanism drug release from the matrices could significantly influence the photostability of NIF in the NIF-ML micellar solution. Lipid matrices are the highly preferred means of providing controlled and sustained release. In order to evaluate the correlation between drug release and the photostability, the cumulative release profiles of NIF from the $1: 1 ; 1: 4$ and 1:9 w/w NIF-ML matrices were studied.

The release of NIF from the monoglycerides matrix involved an initial rapid release phase, which was followed by a phase of relatively slow release (Figure 6).

The NIF-ML matrices released $30-40 \%$ of the drug within the first $15 \mathrm{~min}$. The rapid release of the drug, or drug burst, during the first 15 min suggests that a significant part of the NIF was adsorbed onto the external surface of the monoglycerides matrix. The release of NIF from the matrices after the 15 min was significantly sustained. The 1:9 w/w NIF-ML matrix released only $50 \%$ of the drug over the period of 3 hours indicating a good correlation between drug release from the matrix and the photostability data.

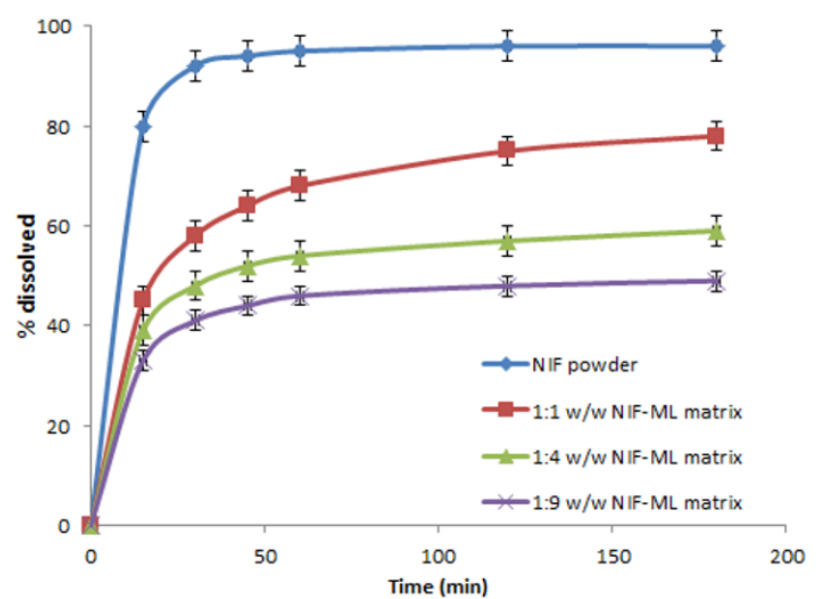

Fig. 6: Cumulative release profiles of NIF from 1:1; 1:4 and 1:9 w/w NIF-ML matrices.

\section{CONCLUSION}

Thermal and microscopic analysis confirmed that nifedipine is in amorphous form in 1:4 and 1:9 w/w NIF-ML matrices, whereas it is partly crystallized to a metastable form when the lipid-to-drug-ratio is reduced to $1: 1$.

The results of the irradiation study show that the inclusion of nifedipine in the monoglycerides matrix has increased its photostability. The 1:1, 1:4 and 1:9 w/w NIF-ML systems have shown a high degree of protection, with degradation rates lower than the drug alone. The micellar solutions have increased the drug half-life by 7-times as compared to the aqueous solution of NIF. The systems herein studied appear of paramount interest for the development of new pharmaceutical formulations of NIF or other photosensitive drugs.

\section{ACKNOWLEDGEMENTS}

The authors would like to acknowledge the financial support from Drake University Research Grant, the American Association of Colleges of Pharmacy, New Investigator Award (AACP-NIA) and Iowa NASA EPSCoR grants.

\section{REFERENCES}

Aman W, Thoma K. ICH guideline for photostability testing: Aspects and directions for use. Pharmazie, 2003; 58:877-880.

Aman W, Thoma K. The influence of formulation and manufacturing process on the photostability of tablets. IntJPharm, 2002; 243:33-41. DOI:10.1016/S0378-5173(02)00110-2

Bayomi M, Abanumay K,Al-Angary A. Effect of inclusion complexation with cyclodextrins on photostability of nifedipine in solid state. IntJPharm, 2002; 243:107-117. DOI: 10.1016/S0378-5173(02) 00263-6

Bechard SR, Quraishi O,Kwong E. Film coating - effect of titanium-dioxide concentration and film thickness on the photostability of 
nifedipine. Int J Pharm, 1992; 87:133-139. DOI: 10.1016/0378-5173(92) 90236-U.

Chan KLA, Fleming OS, Kazarian SG, Vassou D, Chryssikos GD,Gionis V. Polymorphism and devitrification of nifedipine under controlled humidity: a combined FT-Raman, IR and Raman microscopic investigation. J Raman Spectrosc, 2004;35:353-359. DOI: 10.1002/ jrs.1139.

Dahan A, Beig A, Ioffe-Dahan V, Agbaria R,Miller J. The twofold advantage of the amorphous form as an oral drug delivery practice for lipophilic compounds: Increased apparent solubility and drug flux through the intestinal membrane. AAPS Journal, 2013; 15:347. DOI: 10.1208/s12248-012-9445-3.

Dang W, Daviau T,Brem H. Morphological characterization of polyanhydride biodegradable implant Gliadel during in vitro and in vivo erosion using scanning electron microscopy. Pharm Res, 1996; 13:683691. DOI: $10.1023 / \mathrm{A}: 1016035229961$.

Gambhire MS, Bhalekar MR, Shrivastava B. Investigations in photostability of dithranol incorporated in solid lipid nanoparticles. Pharm Chem J, 2012; 46:256-261. DOI: 10.1007/s11094012-0774-4.

Gan L, Han S, Shen JQ, Zhu JB, Zhu CL, Zhang XX,Gan Y. Self-assembled liquid crystalline nanoparticles as a novel ophthalmic delivery system for dexamethasone: Improving preocular retention and ocular bioavailability. Int $J$ Pharmaceut, 2010; 396:179-187. DOI: 10.1016/j.ijpharm.2010.06.015.

Gerald M. 2005. AHFS Drug Information. Bethesda MD. American Society of Health-System Pharmacists.

Gil-Agusti M, Carda-Broch S, Monferrer-Pons L,EsteveRomero J. Photostability studies for micellar liquid chromatographic determination of nifedipine in serum and urine samples. Biomed Chromatogr, 2006; 20:154-160. DOI: 10.1002/bmc.541.

Goerner H. Nitro group photoreduction of 4-(2-nitrophenyl)and 4-(3-nitrophenyl)-1,4-dihydropyridines. ChemPhys, 2010; 373:153158. DOI: $10.1016 /$ j.chemphys.2010.06.007.

Grooff D, Francis F, De Villiers MM, Ferg E. Photostability of crystalline versus amorphous nifedipine and nimodipine. J Pharm Sci, 2013; 102:1883-1894. DOI: 10.1002/jps.23533.

Grundy JS, Kherani R,Foster RT. Sensitive high-performance liquid-chromatographic assay for nifedipine in human plasma utilizing ultraviolet detection. $J$ Chromatogr B, 1994a; 654:146-151. DOI: 10.1016/0378-4347(93)E0449-Z.

Grundy JS, Kherani R,Foster RT. Photostability determination of commercially available nifedipine oral dosage formulations. $J$ Pharm Biomed Anal, 1994b; 12:1529-1535. DOI: 10.1016/0731-7085(94)001006 .

Gunn E, Guzei IA, Cai T,Yu L. Polymorphism of nifedipine: Crystal structure and reversible transition of the metastable beta polymorph. Cryst Growth Des, 2012; 12:2037-2043. DOI: $10.1021 / \mathrm{cg} 3000075$.

Hayase N, Inagaki S,Abiko Y. Effects of photodegradation products of nifedipine: The nitroso-derivative relaxes contractions of the rat aortic strip induced by norepinephrine and other agonists. JPharmacolExpTher, 1995; 275:813-821.

Helin M, Kontra K, Naaranlahti T,Wallenius K. Content uniformity and stability of nifedipine in extemporaneously compounded oral powders. Am J Health-Syst Ph, 1998; 55:1299-1301.

Hirayama F, Wang Z,Uekama K. Effect of 2-hydroxypropylbeta-cyclodextrin on crystallization and polymorphic transition of nifedipine in solid-state. PharmRes, 1994; 11:1766-1770. DOI: 10.1023/ A:1018971501909.

ICH. Stability testing: Photostability testing of new drug substances and products. Q1B. Fed Regist, 1997; 62:27115-27122.

Kawabe Y, Nakamura H, Hino E,Suzuki S. Photochemical stabilities of some dihydropyridine calcium-channel blockers in powdered pharmaceutical tablets. JPharmBiomedAnal, 2008; 47:618-624. DOI: 10.1016/j.jpba.2008.01.042.

Kiss D, Zelkó R, Novák C,Éhen Z. Application of DSC and NIRS to study the compatibility of metronidazole with different pharmaceutical excipients. $J$ Therm Anal Calorim, 2006; 84:447-451. DOI: $10.1007 / \mathrm{s} 10943-005-7257-9$.

Lai J, Chen JM, Lu Y, Sun J, Hu FQ, Yin ZN,Wu W. Glyceryl monooleate/poloxamer 407 cubic nanoparticles as oral drug delivery systems: I. In vitroevaluation and enhanced oral bioavailability of the poorly water-soluble drug simvastatin. AAPS Pharm Sci Tech, 2009; 10:960-966. DOI: 10.1208/s12249-009-9292-4.

Latosińska JN, Latosińska M, Seliger J,Zagar V. An innovative method for the non-destructive identification of photodegradation products in solid state: 1H-14N NMR-NQR and DFT/QTAIM study of photodegradation of nifedipine (anti-hypertensive) to nitrosonifedipine (potential anti-oxidative). EurJPharmSci, 2012; 47:97-107. DOI 10.1016/j.ejps.2012.05.001

Li N, Kommireddy DS, Lvov Y, Liebenberg W, Tiedt LR,De Villiers MM. Nanoparticle multilayers: Surface modification of photosensitive drug microparticles for increased stability and in vitro bioavailability. J Nanosci Nanotechno, 2006; 6:3252-3260. DOI: 10.1166/jnn.2006.421.

Maafi W, Maafi M. Modelling nifedipine photodegradation, photostability and actinometric properties. IntJPharm, 2013; 456:153-164. DOI: 10.1016/j.ijpharm.2013.07.075.

Maggi L, Machiste E, Fasani E, Albini A, Segale L,Conte U. Photostability of extended-release matrix formulations. Eur $J$ Pharm Biopharm, 2003; 55:99-105. DOI: 10.1016/S09396411(02)00123-1.

Marciniec B, Rychcik W. Kinetic analysis of nifedipine photodegradation in the solid state. Pharmazie, 1994; 49:894897.

Matsuda Y, Teraoka R,Sugimoto I. Comparative evaluation of photostability of solid-state nifedipine under ordinary and intensive light irradiation conditions. IntJPharm, 1989; 54:211-221. DOI: 10.1016/03785173(89)90098-7.

Matsuura I, Imaizumi M,Sugiyama M. Method of kinetic analysis of photodegradation: nifedipine in solutions. Chem Pharm Bull, 1990; 38:1692-1696. DOI: 10.1248/cpb.38.1692.

Ohkubo T, Noro H,Sugawara K. High-performance liquidchromatographic determination of nifedipine and a trace photodegradation product in hospital prescriptions. JPharm Biomed Anal, 1992; 10:67-70. DOI: 10.1016/0731-7085(92)80012-C.

Patel MR, Patel RB, Parikh JR,Patel BG. Improving the isotretinoin photostability by incorporating in microemulsion matrix. ISRN Pharm, 2011; 2011:838016-838016. DOI 10.5402/2011/838016.

Pawar AP, Shelake MR, Bothiraja C,Kamble RN. Development of photostable gastro retentive formulation for nifedipine using lowdensity polypropylene microporous particles. JMicroencapsul, 2012; 29:409-416. DOI: 10.3109/02652048.2012.655330.

Sapino S, Carlotti ME, Cavalli R, Ugazio E, Berlier G, Gastaldi L,Morel S. Photochemical and antioxidant properties of gamma-oryzanol in beta-cyclodextrin-based nanosponges. J Incl Phenom Macro, 2013; 75:69-76. DOI: 10.1007/s10847-012-0147-3.

Sato K. Crystallization behaviour of fats and lipids - a review. Chem Eng Sci, 2001; 56:2255-2265. DOI: 10.1016/S0009-2509(00)00458-9.

Shamsipur M, Hemmateenejad B, Akhond M, Javidnia K,Miri R. A study of the photo-degradation kinetics of nifedipine by multivariate curve resolution analysis. JPharmBiomedAnal, 2003; 31:1013-1019. DOI: 10.1016/S0731-7085(02)00710-0.

Shende MA, Markandeeywar T. Photostability studies and development of fast release nifedipine tablets. Int J Pharm Bio Sci, 2010, $1: 1-14$.

Squillante E, Needham T,Zia H. Solubility and in vitro transdermal permeation of nifedipine. Int J Pharm, 1997; 159:171-180 DOI: 10.1016/S0378-5173(97)00282-2.

Teraoka R, Otsuka M,Matsuda Y. Evaluation of photostability of solid-state dimethyl 1,4-dihydro-2,6-dimethyl-4-(2-nitro-phenyl)-3,5pyridinedicarboxylate by using Fourier-transformed reflection-absorption infrared spectroscopy. Int J Pharm, 1999a; 184:35-43. DOI: 10.1016/ S0378-5173(99)00089-7. 
Teraoka R, Otsuka M, Matsuda Y. Evaluation of photostability of solid-state nifedipine by using Fourier transformed reflectionabsorption infrared spectroscopy. Photochem Photobiol, 1999b; 69:22S$22 \mathrm{~S}$.

Thoma K, Kubler N. Influence of excipients on the photodegradation of drug substances. Pharmazie, 1997; 52:122-129.

Tønnesen HH. Formulation and stability testing of photolabile drugs. Int J Pharm, 2001; 225:1-14. DOI: 10.1016/S0378-5173(01)007463.

Wu GJ, Liang YB, Wang LF, Ma XY,Xing JF. Photodegradation-assay method of nifedipine and its application to studies on percutaneous absorption. Acta Pharmaceutica Sinica, 1993; 28:626628.

\section{How to cite this article:}

Mallory Tough, Abebe Mengesha. Photostability of nifedipine in monolaurin solid matrix and micellar solution. J App Pharm Sci, 2015; 5 (02): 066-073. 